\title{
Hybrid external fixation for neglected fractures of the distal radius: results after one year
}

\author{
Paweł Grala $\cdot$ Wojciech Zieliński
}

Received: 27 February 2008 / Accepted: 28 June 2008/Published online: 19 September 2008

(c) Springer-Verlag 2008

\begin{abstract}
Background External fixation is a well-established procedure for the treatment of unstable fractures of the distal radius, but its use is beset with complications. A plethora of theoretical and experimental data suggests that nonbridging fixators are superior for this setting. A new concept for the use of hybrid external fixation seemed reasonable and was applied for this study.

Materials and methods We report on the first 14 cases of unstable, extraarticular fractures of the distal radius with a one-year follow-up and describe the operative technique. All were treated at 3-5 weeks after injury; nevertheless, closed reduction after the fixator elements were fixed to the bone was always possible.

Results We had no intraoperative complications, but in the follow-up period three cases of algodystrophy and one transient irritation of the ulnar nerve ensued. One case developed superficial infection at the K-wire entry site that resolved with local care and systemic antibiotics. No redisplacements were observed. Early and late (at one year) evaluation of results revealed good and very good anatomic results (Lidström system) and two satisfactory (cases with algodystrophy), eight very good and four good functional outcomes (Gartland-Werley system). The patients' acceptance of the device was high.

Conclusions Hybrid external fixation of neglected distal radial fractures results in good outcomes if care is taken to prevent overdistraction of bone fragments.
\end{abstract}

P. Grala $(\bowtie) \cdot$ W. Zieliński

Department of Trauma, Burns and Plastic Surgery, Poznan University of Medical Sciences, Poznan, Poland

e-mail: pawel.grala@aoalumni.org
Keywords Fracture of the distal radius . Hybrid external fixation

\section{Introduction}

Among many methods established for the treatment of fractures of the distal radius (DRF), different forms of external fixation have proven effective. This approach allows proper reduction and its maintenance throughout the healing of the radius. It results in good anatomical results after union, associated with the restoration of unrestricted function of the upper extremity [1-20].

The most common instrumentation used, restores the anatomy of the distal forearm by continuous ligamentotaxis across the radiocarpal joint. It is also effective in simple intraarticular fractures without additional manipulation [18, 21-23]. Various designs of transarticular ("bridging") fixators have been invented; they are easy to apply, allowing some postoperative adjustments, and are fairly well tolerated by patients $[1,4,5,7-9,13,24]$. The classic transarticular external fixation may cause serious problems associated with its design. The most common, such as hand and finger stiffness ("claw hand") or reflex sympathetic dystrophy, are probably caused by prolonged excessive ligamentotaxis with distraction of the carpus; positioning of distal Shantz screws into the II and III metacarpals can cause serious hand problems like infection and bone fracture $[1,4-7,9,13,14,25,26]$. In addition, the restoration of an important anatomic feature of the distal radius- the palmar tilt-is difficult or sometimes impossible without an additional approach to the distal radius $[1,4,8,9,13$, $14,18,20,25-27]$.

This investigation, performed in a prospective fashion, was aimed to evaluate the anatomical and functional 


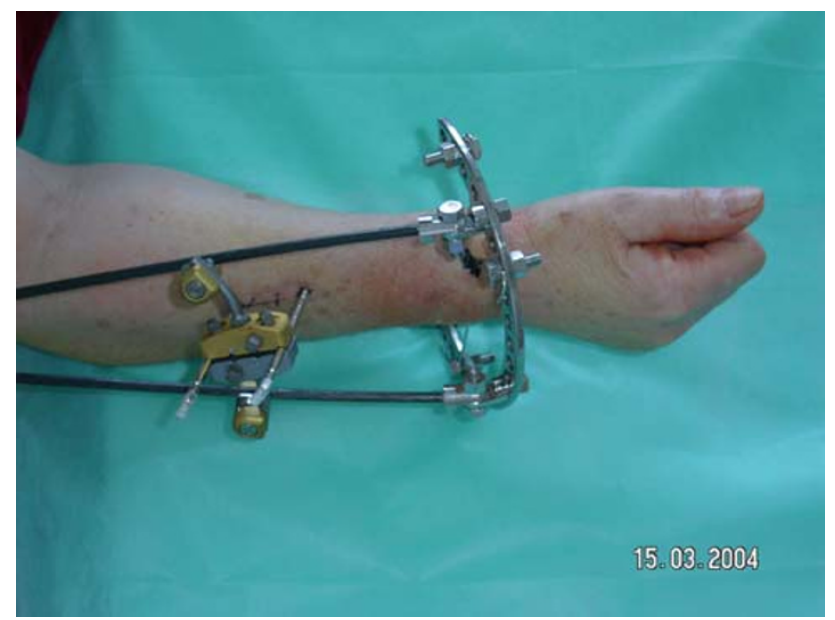

Fig. 1 Hybrid external fixation of a distal radial fracture

consequences of the application of a modified hybrid external fixator (HEF) for certain types of neglected and unstable DRF (Fig. 1).

HEF was originally designed and approved by AO/ASIF for the treatment of distal and proximal tibial fractures [16]. We took up this study under the assumption that combining the advantages of circular Ilizarov fixator and those of unilateral frame construction with the ability to allow immediate postoperative hand motion should yield good anatomic and functional results. We became additionally encouraged by the reports based on cadaveric studies defining the safe zones of pin placement in the ultradistal forearm and characterizing the mechanical properties of various constructs of classic and hybrid fixators, concluding that the good mechanical performance of hybrid fixators justifies their use [28-33].

\section{Materials and methods}

The goal and methods of the study were approved by the ethical board of Poznan University of Medical Sciences in Poland and are in accordance with the Declaration of Helsinki. We report on the late outcomes of 14 cases of DRF treated with HEF. All sustained comminuted extrarticular fractures with significant displacement of the distal fragment, and gave informed consent to be enrolled to the current study. There were nine females aged 34-70 and five males aged 39-56 (Table 1). The use of HEF was always a secondary choice, after failed attempts at conservative treatment. Fractures were classified according to the AO classification system [34]. All were considered unstable because of marked dorsal or volar comminution, angular deformity exceeding $20^{\circ}$, osteoporosis or redisplacement after previous satisfactory reduction. The operation was performed under general anesthesia or brachial plexus block (optional upon patient-anesthesiologist agreement) after 2 5 weeks from injury (mean: 3 ).

Placement of $1.8 \mathrm{~mm} \mathrm{~K}$-wires into the distal fragment was performed through "safe zones," as suggested by Lindsay and Ludvigsen, with the forearm supinated (Fig. 1) $[30,32]$. No targeting device was used. The two proximal 4.0-mm halfpins (predrilled, self-tapping) were placed through a limited open approach between the brachioradialis and extensor carpi radialis longus muscles at the level of their myocutaneous junction. Our construction consisted of an Ilizarow $3 / 5$ ring forming a base for two Kirschner wires with olives entirely supporting the distal fragment (steel: MasterMed, Kraków, Poland; or carbon fiber: Synthes, Solothurn, Switzerland) attached with a self-designed adapter to the

Table 1 Anatomic and functional results of treatment with the hybrid external fixator in patients with neglected fractures of the distal radius

\begin{tabular}{|c|c|c|c|c|c|c|c|}
\hline No./sex & Age & $\begin{array}{l}\text { Fracture } \\
\text { classification } \mathrm{AO}\end{array}$ & $\begin{array}{l}\text { Lidström score } \\
\text { postoperatively/at } \\
\text { one year }\end{array}$ & Grading & $\begin{array}{l}\text { Gartland-Werley } \\
\text { score at one year }\end{array}$ & Grading & Complications \\
\hline 1./F & 56 & A 3.2 & $0 / 0$ & Very good & 2 & Very good & Superficial infection \\
\hline 2./F & 70 & A3.2 & $0 / 1$ & Good & 2 & Very good & \\
\hline 3./M & 41 & A 3.1 & $0 / 0$ & Very good & 5 & Good & \\
\hline 4./F & 42 & $\mathrm{~A} 2.2$ & $1 / 1$ & Good & 10 & Fair & Algodystrophy \\
\hline 5./F & 62 & A 3.1 & $0 / 0$ & Very good & 1 & Very good & \\
\hline $6 . / \mathrm{F}$ & 34 & A 3.3 & $1 / 1$ & Good & 2 & Very good & \\
\hline 7./F & 69 & A 3.3 & $1 / 2$ & Good & 4 & Good & \\
\hline 8./M & 39 & A 2.3 & $2 / 2$ & Good & 4 & Good & \\
\hline 9./M & 42 & A3.1 & $1 / 0$ & Very good & 9 & Fair & Algodystrophy \\
\hline 10./F & 39 & A2.3 & $0 / 0$ & Very good & 1 & Very good & \\
\hline 11./F & 49 & A3.1 & $0 / 0$ & Very good & 0 & Very good & \\
\hline 12./M & 50 & A 3.3 & $0 / 0$ & Very good & 8 & Good & Algodystrophy \\
\hline 13./F & 62 & A.3.2 & $1 / 3$ & Good & 3 & Good & \\
\hline 14./M & 56 & A2.3 & $0 / 0$ & Very good & 2 & Very good & \\
\hline
\end{tabular}




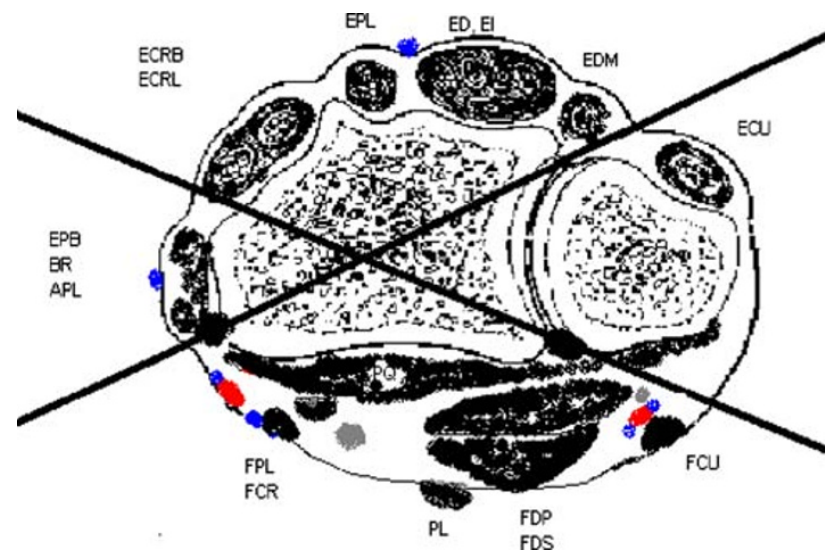

Fig. 2 Safe zones for K-wire placement in the ultradistal forearm; black muscles; red arteries; blue veins; gray nerves

unilateral two bar/pin assembly (Stryker Howmedica Osteonics, Kalamazoo, MI, USA) (Fig. 2). The procedure was performed under radiographic control with closed reduction after the implant was attached to both main bone fragments [35]. In principle, the fixator was removed after eight weeks.

In the early postoperative period (two days), daily dressing changes at the implant-skin interface were performed and flexion-extension wrist motion was encouraged from the second postoperative day. Patients were dissuaded from rotational exercises. Routine clinical and radiographic evaluations were performed postoperatively on the second or third day (discharge from hospital), and then after 2, 8, and 14 weeks and one year. The anatomic end results were evaluated with the Lidström system, and functional results were evaluated using the Gartland-Werley system modified by Sarmiento [36, 37].

\section{Results}

All fractures healed and results of anatomic and functional evaluation are presented in Table 1 . Early removal of the fixator was needed in one case (after six weeks, followed by a dorsal splint for ten days), complicated with superficial infection at the site of the K-wire/skin contact area. The infection developed at four weeks postoperatively with swelling of the forearm, pain and fever. Control of the infection was achieved with debridement of the K-wire entry site and wide-spectrum systemic antibiotics.

The patients without complications (ten) had no problems with early postoperative flexion-extension range of motion exercises.

In four cases, overdistraction of bone ends was detected on postoperative X-ray (Fig. 3). Painless postoperative adjustments of the fixator restored normal anatomy, but only one patient was free of complications. In three of them, severe algodystrophy ensued. All had classic physical (sudomotor

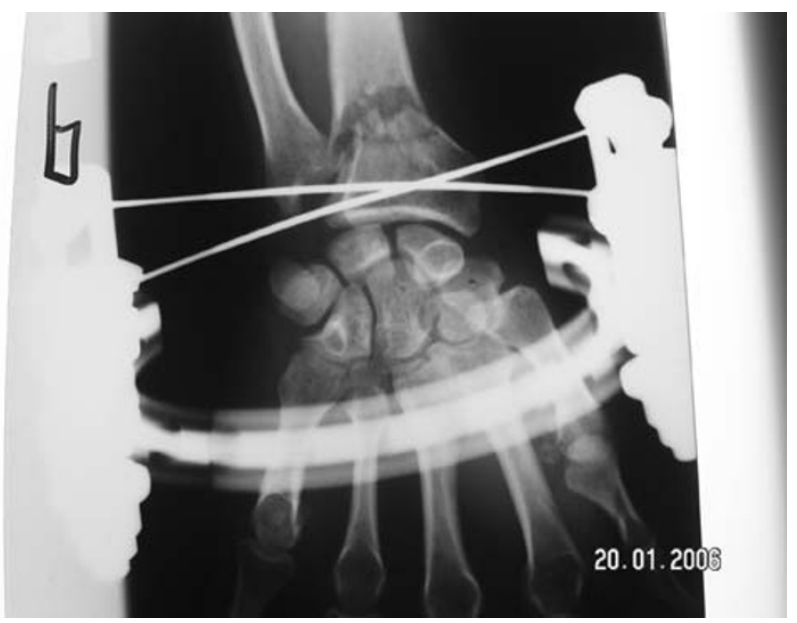

Fig. 3 Overdistraction of bone ends

and vasomotor instability) and radiographic findings supporting the diagnosis (Fig. 4). Such cases had electromyographic studies performed within the first three months. Significantly decreased amplitude of motor response in the median nerve and slowed conduction in its motor fibers suggested advanced axonopathy of the median nerve.

One case of transient neuropathy of the ulnar nerve complicated the introduction of a K-wire from the ulnopalmar direction. Symptoms of nerve irritation were evident during introduction of the wire, so the site was changed to a more ulnar location. Symptoms resolved completely within three months.

\section{Discussion}

Sufficient experience and a thorough knowledge of distal forearm anatomy along with the "safe zones" for Ilizarov

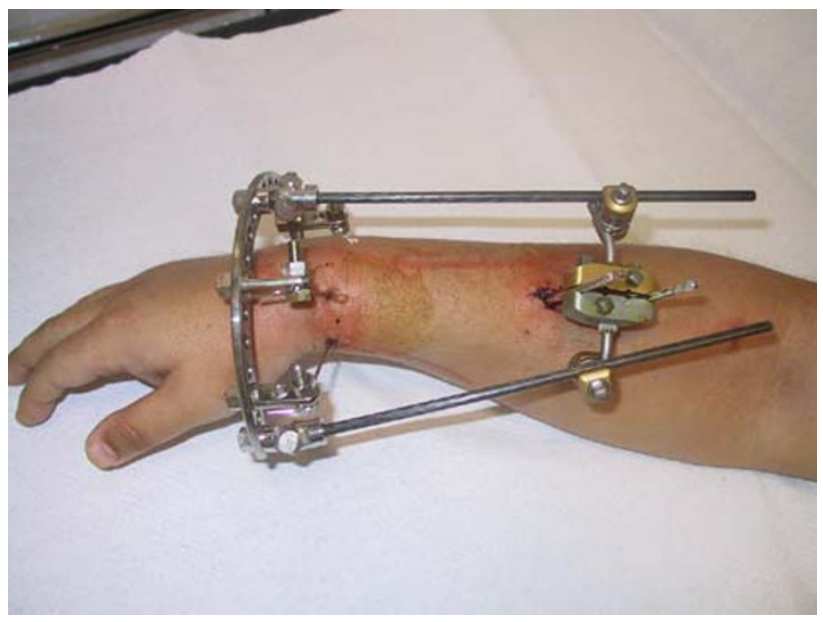

Fig. 4 Ilizarov 3/5 steel ring mounted on the distal bone fragment with extensions for good lateral radiographic visualization of the radiocarpal articular slope 
K-wire placement allows undisturbed fixation of main fracture fragments to the external fixator [30, 32, 35]. Later manipulation of the distal fragment attached to the ring is effective, yet overdistraction is a present threat. If left undetected it may lead to algodystrophic complications, probably due to injury to the median nerve, as was proven by our three cases in electromyographic studies. Other causes that are often cited in the literature cannot be negated, because the cases studied here represent a selected group of high-risk patients. Identified risk factors were: localization of injury, multiple previous manipulations for fracture reduction with local anesthesia (hematoma block), and one case of excessive tightness of the cast [38-44].

Excessive distraction of bone fragments is often not visible during the operation (reduction is the final step) and is camouflaged by K-wire elasticity. In all of our cases, the immediate (up to $1 \mathrm{~h}$ ) postoperative $\mathrm{X}$-ray examination revealed the problem, but this tendency existed to the second postoperative day. Quick correction of overdistraction is easy, even postoperatively, because it only requires loosening of the ring/bar fixation screw, allowing automatic adjustment of the distracted tissues. Overdistraction is especially likely to develop, if operative intervention is late (up to five weeks after fracture).

To prevent the fixator's ring from interference with lateral radiograms, we used a commercially available composite carbon ring or a less expensive solution-mounting the $\mathrm{K}$-wires on a special extension at the ring (Fig. 5). Contrary to Lindsay, we do not consider the possibility of ulnar head impingement to be of clinical concern. In our opinion, such impingement offers a dynamic buttressing effect in cases of distal radioulnar joint (DRUJ) instability-common after DRF $[2,12,16,30]$.

Postoperatively, patients were allowed to perform nonweight-bearing daily activities with the injured extremity, but forceful rotation of the forearm was discouraged because of possible occult DRUJ injuries [45, 46].
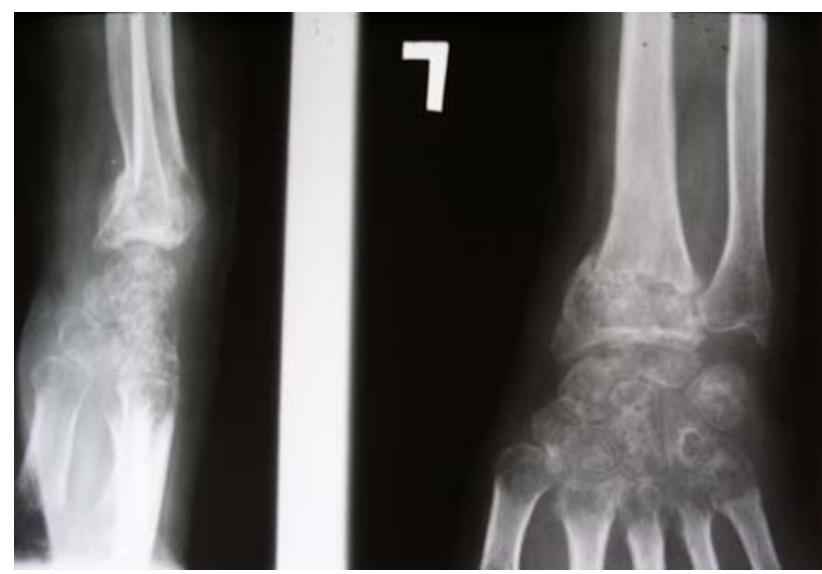

Fig. 5 Severe algodystrophy manifested on an X-ray
No problems with soft tissue healing were observed, despite the proximity of a K-wire olive to the skin surface. In one case of superficial infection, the inflammatory process was similarly intensive at two sites: one with the olive and the other without [35].

Elimination of ligamentotaxis for reduction prevents problems with hand stiffness and allows late intervention. Three-dimensional, direct, closed control of the distal fragment with anatomic restoration of radial length, volar tilt, and radial inclination is the biggest advantage of the fixator described above. Other methods of transarticular external fixation cannot exert sufficient longitudinal traction to reduce neglected fractures, since they would cause distraction of the carpus instead $[1,7,14-16,25,26]$. In vivo studies, found reduction with a nonbridging fixator to be much more effective than with bridging, due to direct control of the distal fragment (similar to the mechanism seen in HEF), which is especially valuable for restoring the volar tilt $[15,20]$. On the other hand, one important disadvantage is the lack of a "traction view" typical of bridging fixators, which visualizes occult midcarpal ligamentous injuries that might require early surgery [31]. There are, however, contrary opinions saying that distraction of scapholunate joint may be detrimental to ligamentous healing [13].

No or negligible loss of postoperative reduction proves the good stability of bone fragments fixed with HEF. The same conclusions have been reached on cadaveric specimens with severely unstable DRFs fixed by HEF. Laboratory investigation found such construction to be stable, with loading patterns similar to those found in living subjects [30-32, 47].

The two reinforcing struts, connected the free end of the unilateral body to the ring forming two triangular structures, greatly reducing the deformation of the unilateral body and its adapter, and thus increasing the rigidity of the construct. It should be emphasized that in vivo interfragmentary motion is affected by the forces applied to the bone, the mechanical properties of fixation devices, the fracture pattern, the quality of fracture reduction, and the surrounding soft tissues [16, 29, 30, 33, 47, 48]. An important finding from previous reports- that wire crossing angles of the Ilizarov fixator of $90^{\circ}$ give the highest bending stiffness - cannot be achieved in the distal radius due to anatomical restrictions: safe zones [32, 48].

The dependence of the Ilizarov fixator on tensioned fine wires that transfix the bone in a multiplanar and coaxial fashion with its relative axial flexibility is considered beneficial for uniform callus formation, while the increased stiffness at higher loads protects the fracture from excessive movement. The combination of all of these attributes may in part explain the short fracture healing times reported by Ilizarov and others [28, 48, 49]. All of our 
cases healed without delay, so we did not consider it necessary to add an additional ring or "drop wire" for increased stiffness.

Problems reported with forced and prolonged immobilization of the hand in flexion are avoided because HEF restricts all fixation to the radius. The hand is left free, and early active motion of the wrist is possible in uncomplicated cases. There is general consent that early hand function is beneficial for bone and articular cartilage healing, as well as advantageous for the surrounding soft tissues [3, 26, 28-30, 32, 50]. The aforementioned advantage was the reason for the invention of other nonbridging (radio-radial) constructions. Their use might be associated with mechanical problems (most require the distal fragment to be broad enough to accommodate two threaded pins-about $2 \mathrm{~cm}$ ) or, like the device invented by Gradl, initial bridging external fixation, thus excluding inveterate cases $[3,5,13,14,20,26,28]$. The use of hinged, bridging fixators to mobilize the hand early was found to be technically difficult and is associated with a redislocation rate that reaches $28 \%$, even if dorsiflexion is limited $[49,50]$. Thus, the hybrid construction used in this study appears a reasonable answer to these problems.

Periods of immobilization vary in different studies from five to ten weeks. We have chosen eight weeks as the removal time, as this was shown in other studies to be enough for sufficient stability [5, 8, 9, 12, 25, 33, 50].

None of our patients have been evaluated for osteoporosis, but considering the age, gender and mechanism of injury, we can expect that the bone quality in this group was sometimes poor. It did not affect the stability of the fracture, probably due to the high degree of purchase that the two K-wires of the fixator obtained in the distal fracture fragment. These achieve a strong interference fit in the relatively dense subchondral bone of the distal radius, and their crossed configuration provides a stable interface with the bone $[33,48]$.

The very good and good functional results (except for the three cases with algodystrophy) obtained after a oneyear follow-up period, match well with those from the study of Gradl (20 excellent results, three good and one fair), who used similar technique but as a primary treatment method [20].

Our results suggest that hybrid external fixation of neglected fractures of the distal radius is an effective and safe method for their reduction and stable fixation, but that overdistraction of bone fragments should be avoided.

Conflict of interest statement No benefits in any form have been or will be received from a commercial party related directly or indirectly to the subject of this article. No funds were received in support of this study.

\section{References}

1. Hove LM, Furnes O, Nilsen PT, Ouile HE, Solheim E, Molster AO (1997) Closed reduction and external fixation of unstable fractures of the distal radius. Scand J Plast Reconstr Hand Surg 31:159-164

2. Ark J, Jupiter BJ (1993) The rationale for precise management of distal radius fractures. Orthop Clin North Am 24:205-209

3. Agee JM (1993) External fixation. Technical advantages based upon multiplanar ligamentotaxis. Orthop Clin North Am 24:265274

4. Cronier P, Talha A, Toulemonde JL, Jaeger F, Guntz M (1991) Resultats de la distraction par fixateur externe metacarporadial dans les fractures de l'extremite distale du radius. [The results of distraction by metacarpo-radial external fixator in fractures of the distal radius]. J Chir (Paris) 128(1):8-12

5. Van Dijk JP, Laudy FGJ (1996) Dynamic external fixation versus nonoperative treatment of severe distal radial fractures. Injury 27:57-61

6. Horesh Z, Volpin G, Hoerer D, Stein H (1991) The surgical treatment of severe comminuted intraarticular fractures of the distal radius with the small AO external fixation device. Clin Orthop 263:147-153

7. Howard PW, Stewart HD, Hind RE, Burke FD (1989) External fixation or plaster for severely displaced comminuted Colles' fractures? A prospective study of anatomical and functional results. J Bone Joint Surg Br 71:68-73

8. McQueen MM (1998) Redisplaced unstable fractures of the distal radius. A randomised prospective study of bridging versus nonbridging external fixation. J Bone Joint Surg Br 80:665-669

9. Melone CP (1993) Distal radius fractures: patterns of articular fragmentation. Orthop Clin North Am 24:239-253

10. Raskin KB, Melone CP Jr (1993) Unastable articular fractures of the distal radius. Comparative techniques of ligamentotaxis. Orthop Clin North Am 24:275-286

11. Szabo RM (1992) Comminuted distal radius fractures. Orthop Clin North Am 23:1-5

12. Simic PM, Weiland AJ (2003) Fractures of the distal aspect of the radius: changes in treatment over the past two decades. J Bone Joint Surg Am 85:552-564

13. Kongsholm J, Olerund C (1989) Plaster cast versus external fixator for unstable intraarticular Colles' fractures. Clin Orthop 241:57-65

14. Weber SC, Szabo RM (1986) Severely comminuted distal radial fracture as an unsolved problem: complications associated with external fixation and pins and plaster techniques. J Hand Surg Am $11: 157-165$

15. Kaempffe FA, Wheeler DR, Peimer CA, Hvisdak KS, Ceravolo J, Senall J (1993) Severe fractures of the distal radius: effect of amount and duration of external fixator distraction on outcome. $\mathrm{J}$ Hand Surg Am 18:33-41

16. Pugh KJ, Wolinsky PR, Pienkowski D, Banit D, Dawson JM (1999) Comparative biomechanics of hybrid external fixation. J Orthop Trauma 13(6):418-425

17. Ziegler JP, Remigier A (1995) The treatment of unstable fractures of the distal end of the radius with a radioradial external fixator and functional aftertreatment. J Bone Joint Surg Br 77(Suppl I)

18. Rikli DA, Küpfer K, Bodoky A (1998) Long-term results of the external fixation of distal radius fractures. J Trauma 44(6):970976

19. Cooney WP (1998) Distal radius fractures: external fixation proves best. J Hand Surg 23A:1119-1121

20. Gradl G, Steinborn M, Wizgall I, Mittlmeier T, Schurmann M (2003) Acute CRPS I (morbus sudeck) following distal radial 
fractures-methods for early diagnosis. Zentralbl Chir 128(12):1020-1026

21. Melone CP (1984) Open treatment for displaced articular fracture of the distal radius. Clin Orthop 202:103-111

22. Fernandez DL, Geissler WB (1991) Treatment of displaced articular fractures of the radius. J Hand Surg Am 16:375-384

23. Jupiter JB, Lipton H (1993) The operative treatment of intraarticular fractures of the distal radius. Clin Orthop 292:48-61

24. Seitz WH (1993) External fixation of distal radius fractures. Indications and technical principles. Orthop Clin North Am 24:255-264

25. Rikli DA, Rosenkranz J, Regazzoni P (2003) Complex fractures of the distal radius. Eur J Trauma 29:199-207

26. McQueen MM, Michie M, Court-Brown CM (1992) Hand and wrist function after external fixation of unstable distal radial fractures. Clin Orthop 285:200-204

27. Dienst M, Wozasek GE, Seligson D (1997) Dynamic external fixation for distal radius fractures. Clin Orthop 338:160-171

28. Salter RB (1989) The biologic concept of continuous passive motion on synovial joints: the first 18 years of research and its clinical application. Clin Orthop 242:12-25

29. Ludvigsen YC, Wentorf F, Wolf T, Puynam MD (1999) Hybrid fixation of distal radius fractures. Presented at: 1999 AAOS Annual Meeting, Scientific Program: Hybrid Fixation, Anaheim, CA, USA, 4-8 February 1999

30. Goslings JC, Ferguson SJ, Perren RA, Tepic S (1999) Biomechanical analysis of dynamic external fixation devices for the treatment of distal radial fractures. J Trauma 46(3):407-412

31. Lindsay CS, Richards RS, King GJW, Patterson SD, Hung LK (2001) Ilizarov hybrid external fixation for fractures of the distal radius: part I. Feasibility of transfixation wire placement. J Hand Surg Am 26(2):210-220

32. Dunning CE, Lidsay CS, Bicknell RT, Johnson JA, King GJ, Patterson SD (2001) Ilizarov hybrid external fixation for fractures of the distal radius: part II. Internal fixation versus Ilizarov hybrid external fixation: stability as assessed by cadaveric simulated motion testing. J Hand Surg Am 26(2):218-227

33. Müller ME, Nazarian S, Koch P, Schatzker J (1990) The comprehensive classification of fractures of the long bones. Springer, Berlin, pp 106-115

34. Grala P, Kierzynka G, Machyńska-Bućko Z (2005) Hybryd external fixation of unstable distal radius fractures: initial experience. J Orthopaed Traumatol 6:138-144

35. Lidström A (1959) Fractures of the distal end of the radius. A clinical and statistical study of end results. Acta Orthop Scand Suppl 41:1-118
36. Gartland JJ Jr, Werley CW (1951) Evaluation of healed Colles' fractures. J Bone Joint Surg Am 33:895-907

37. Sarmiento A, Pratt GW, Berry NC, Sinclar WF (1975) Colles' fractures. Functional bracing in supination. J Bone Joint Surg Am $57: 311-317$

38. Atkins RM, Duckworth T, Kanis JA (1989) Algodystrophy following Colles fracture. J Hand Surg Br 14:161-164

39. Bickerstaff DR, Kanis JA (1994) Algodystrophy: an under-recognized complication of minor trauma. Br J Rheum 33:240-248

40. Zollinger PE, Tuinebreijer WE, Kreis RW, Breederveld RS (1999) Effect of vitamin C on frequency of reflex sympathetic dystrophy in wrist fractures: a randomised trial. Lancet 354:2025-2028

41. Cooney WP, Dobyns JH, Linscheid RL (1980) Complications of Colles' fractures. J Bone Joint Surg Am 62:613-619

42. Field J, Atkins RM (1997) Algodystrophy is an early complication of Colles' fracture. What are the implications? J Hand Surg Br 22(2):178-182

43. Field J, Protheroe DL, Atkins RM (1994) Algodystrophy after Colles fractures is associated with secondary tightness of casts. J Bone Joint Surg Br 76:901-905

44. Dijkstra PU, Groothoff JW, Ten Duis HJ, Geertzen JH (2003) Incidence of complex regional pain syndrome type I after fractures of the distal radius. Eur J Pain 7(5):457-462

45. Cheng SL, Axelrod TS (1997) Management of complex dislocations of the distal radioulnar joint. Clin Orthop 341:183-191

46. Geissler WB, Fernandez DL, Lamey DM (1996) Distal radioulnar joint injuries associated with fractures of the distal radius. Clin Orthop 327:135-146

47. Yang L, Nayagam S, Saleh M (2003) Stiffness characteristics and inter-fragmentary displacements with different hybrid external fixators. Clin Biomech 18(2):166-172

48. Ilizarov GA (1989) The tension-stress effect on the genesis and growth of tissues. Part I. The influence of stability of fixation and soft-tissue preservation. Clin Orthop 238:249-291

49. Penning D, Gausepohl T (1996) External fixation of the wrist. Injury 27:1-15

50. Sommerkamp TG, Seeman M, Silliman J, Jones A, Patterson S, Walker J, et al (1994) Dynamic external fixation of unstable fractures of the distal part of the radius. J Bone Joint Surg Am 76:1149-1161 